\section{Capacitação das equipes locais como estratégia para a institucionalização da avaliação em saúde}

\author{
Training local teams as a strategy to institutionalize \\ evaluation in the health system
}

\author{
1 Universidade Estadual de \\ Maringá, Maringá, Brasil. \\ Correspondência \\ M. J. Scochi \\ Universidade Estadual de \\ Maringá. \\ Av. Colombo 5790, Maringá, $P R$ \\ 87020-900, Brasil. \\ mjscochi@uem.br
}

\begin{abstract}
This article reports on the methodology used by the research team of the State University in Maringá in the Baseline Study in 20 municipalities in the States of Paraná and Santa Catarina, Brazil, with more than 100,000 inhabitants each, in the implementation of the Project for Expansion and Consolidation of the Family Health Strategy. Workshops to discuss the evaluation of programs, construction and application of research instruments, site visits to supervise activities in disseminating the program, and development of a database with the local and regional scientific output were carried out. There was an obvious sense of responsibility and commitment on the part of municipal and State representatives, the majority of whom immediately agreed to the activities. They also showed interest in both the learning process and institutionalization of the evaluation. Fourteen municipalities incorporated other actors to build a support network for the evaluation of the primary health care system. The strategies contributed to the incorporation of evaluation into the planning process, indicating that training can be a constructive and powerful mechanism for institutionalizing evaluation.
\end{abstract}

Primary Health Care; Health Evaluation; Family Health Program; Training.
Maria José Scochi 1

Sonia Silva Marcon 1

Magda Lúcia Félix de Oliveira 1

Maria Angélica Pagliarini Waidman 1

Maria Bernadete Gonçalves 1

Paula Nishiyama 1

Regina Lúcia Dalla Torre Silva ${ }^{1}$

Wladithe Organ de Carvalho 1

\section{Introdução}

O Ministério da Saúde propôs, em 2003, o Projeto de Expansão e Consolidação do Saúde da Família (PROESF), o qual está voltado para a reestruturação da atenção básica e mudança do modelo assistencial em municípios com mais de 100 mil habitantes, com diversos investimentos para induzir mudanças sustentáveis nas práticas, na organização do trabalho e nas redes assistenciais 1 .

Um dos principais pilares do PROESF é a avaliação e o monitoramento como parte da macroestratégia de institucionalização da avaliação. " $O$ incentivo para a formação de uma nova competência e cultura avaliativa (...) ganha relevância ao ser desenhado e construído pelo PROESF por meio do fortalecimento da capacitação técnica das secretarias estaduais de saúde" 2 (p. 14).

Este incentivo poderá mobilizar os sujeitos desde que estes estejam convencidos da importância da avaliação e percebam que ela deve estar no cerne das estratégias para transformação do Sistema Único de Saúde (SUS) 3. Para isso, postula-se como fundamental a apropriação dos diferentes atores municipais, envolvidos com a oferta de serviços de saúde, dos métodos e instrumentos utilizados na avaliação.

Dessa forma, no Estudo de Linha de Base, patrocinado pelo Ministério da Saúde, para avaliar a atenção básica em vinte municípios da Região Sul, a capacitação das equipes locais foi priori- 
zada pela equipe de pesquisa da Universidade Estadual de Maringá (UEM), sob a égide de uma metodologia que pudesse contribuir com a formação de grupos locais de difusão e multiplicação de conhecimento em avaliação, com a constituição de parcerias, bem como com a formação de redes, para promover a troca de experiência entre centros de pesquisa e serviços de saúde com vistas à institucionalização da avaliação 4 . Do processo de capacitação adotado é que trata o presente artigo, cujo objetivo é relatar e analisar a trajetória metodológica adotada.

\section{Pressupostos da proposta}

No desenvolvimento conceitual e metodológico da pesquisa e da capacitação, foram incorporadas as diretrizes da política de avaliação da Coordenação de Acompanhamento e Avaliação da Atenção Básica. De acordo com esta política, a avaliação em saúde teria como propósito fundamental “(...) dar suporte a todo processo decisório no âmbito do Sistema de Saúde (...) devendo subsidiar a identificação de problemas e a reorientação de ações e serviços desenvolvidos, avaliar a incorporação de novas práticas sanitárias na rotina de profissionais e mensurar o impacto das ações implementadas pelos serviços e programas sobre o estado de saúde da população" 1 (p. 7).

A proposta desenvolvida teve como marco conceitual a crença de que, para se conseguir efetivar a prática da avaliação nos municípios, seria necessário que os trabalhadores fossem sensibilizados e envolvidos no processo desde o início, ou seja, na definição dos objetivos e propósitos da avaliação, dos métodos adotados e na construção dos instrumentos a serem utilizados.

Ante a impossibilidade de trabalhar com os atores sociais dos vinte municípios ao mesmo tempo e a necessidade de executar a pesquisa em 12 meses, buscou-se a disseminação de conhecimento e informações com base no conceito de redes sociais, mais especificamente de rede de informações. As redes são sistemas compostos por entrelaçamentos e conexões entre os atores, que, nas ciências sociais, são representados por sujeitos sociais (indivíduos, grupos, organizações, entre outros) conectados por algum tipo de relação 5 .

Estudos sobre decisões gerenciais indicam que a maioria das suas informações vem do contato humano direto. Isso demonstra que esse ainda é o meio mais rápido e eficiente de procurar e acessar informações, mediante o compartilhamento dos conteúdos e contextos dos conhecimentos necessários à decisão 6 .

A eficiência da rede depende da capacidade de cada membro em transmitir uma informação em tempo hábil e de enriquecer as informações. É por isso que a comunicação é fundamental quando se trabalha em rede, pois o modo como o indivíduo se comporta é estabelecido por suas relações com outras pessoas e determina se a rede é fraca ou forte 6 . Os vínculos formados entre os indivíduos têm diversas naturezas, por isso se imaginam as redes em camadas, cada uma das quais associada a um tipo de relação desenvolvida no período. Assim, tentou-se formar um vínculo entre a equipe executora e a equipe local, com o intuito de fortalecer a rede. Por essa razão, o grupo de pesquisa foi estruturado de forma matricial: grupo coordenador, equipe técnica e equipes locais dos municípios dos estados do $\mathrm{Pa}$ raná e Santa Catarina.

O grupo coordenador esteve representado pelos cinco docentes da UEM que apresentaram a proposta ao Ministério da Saúde; a equipe local, por dois representantes de cada um dos municípios em estudo. A equipe técnica foi constituída por sete representantes dos Pólos de Formação e Educação Permanente em Saúde - Preps - (Apucarana, Londrina, Cascavel, Guarapuava, Maringá, Campo Mourão e Curitiba), dois técnicos da Regional de Saúde de Itajaí, mais quatro docentes da UEM. O quadro contou ainda com quatro alunos de pós-graduação, sendo três do mestrado em Enfermagem e um do mestrado em Ciências da Saúde.

Solicitou-se aos representantes das equipes locais que participassem, efetivamente, nas atividades de capacitação e que também trabalhassem em forma de rede em seus respectivos municípios. Portanto, para cada dupla de representantes de município, deveria existir uma equipe de apoio, e esta, ao mesmo tempo em que ajudaria os representantes a cumprir com as tarefas previstas, também seria sensibilizada e capacitada para a atividade de avaliação no município, sendo tal fato considerado na pesquisa como qualificador da adesão do município à proposta de institucionalização da avaliação.

O referencial escolhido para guiar as atividades de investigação baseou-se nos pressupostos das metodologias de Guba \& Lincoln 7 e da pesquisa-ação ${ }^{8}$, pois são métodos que contemplam diversas técnicas numa estrutura coletiva, participativa e ativa no que se refere à captação da informação, tendo como participantes as pessoas envolvidas no problema investigado. Ambas as metodologias pressupõem a realidade como construção social e na intervenção orientada para solucionar os problemas efetivamente detectados na coletividade considerada 9 .

Logo, o princípio que norteou a construção dessa metodologia foi a possibilidade de realização conjunta de uma estratégia de pesquisa 
factível para a maioria dos municípios. Por essa razão, durante todo o processo de pesquisa, foi adotada uma estratégia de construção e validação coletiva dos instrumentos e do método de coleta de dados, a qual foi denominada de Metodologia Convergente Avaliativa. De acordo com ela, a capacitação das equipes locais se dá de forma crescente e no âmbito teórico e prático.

Dessa maneira, ao mesmo tempo em que os membros das equipes locais colhem dados referentes aos seus municípios, eles também contribuem com o processo de validação dos instrumentos utilizados, ao exporem suas dificuldades e as peculiaridades na aplicação de tais instrumentos.

É importante destacar que a própria equipe coordenadora e a equipe técnica também se constituíram como atores desse processo convergente avaliativo e, conseqüentemente, foram capacitadas na construção coletiva do processo de pesquisa. Nesse sentido, antes das atividades com as equipes locais, realizavamse, com a equipe técnica, oficinas de leitura e discussão do projeto, concebidas como espaço para ampliação da discussão conceitual e metodológica, visando a estabelecer um referencial homogêneo entre os participantes da equipe de pesquisa.

\section{Sensibilização e capacitação das equipes locais para a institucionalização da avaliação em saúde}

O processo de institucionalização da avaliação foi trabalhado tendo por base três aspectos: capacitação dos técnicos dos municípios e estados envolvidos, construção coletiva de um banco de dados de produção científica locorregional e criação de espaços de assessoria e difusão do conhecimento em avaliação em saúde.

Os procedimentos operacionais adotados podem ser agrupados em três momentos: prétrabalho de campo, capacitação das equipes locais e pós-trabalho de campo. As estratégias para a sensibilização e capacitação das equipes locais foram: oficinas, atividades de dispersão, elaboração de material didático-pedagógico e visita das equipes coordenadora e técnica aos municípios.

\section{As oficinas com as equipes de pesquisa}

Um primeiro e importante movimento foi a realização da Oficina Macrorregional Sul do Estudo de Linha de Base, promovida pelo Ministério da Saúde e pelos grupos de pesquisa, a qual favoreceu o diálogo entre academia e gestores municipais, bem como uma interlocução entre os diver- sos núcleos de pesquisa envolvidos na proposta. A oficina propiciou o início da parceria técnica e operacional entre os secretários municipais de saúde, coordenadores estaduais e municipais da Atenção Básica e da saúde da família e representantes da UEM, permitindo a pactuação inicial de estratégias de cooperação.

Nesse encontro, a equipe de pesquisa distribuiu um questionário semi-estruturado, de autopreenchimento, aos representantes indicados pelos municípios para acompanhamento do Estudo de Linha de Base. O objetivo era (re)conhecer o grupo local, subsidiando o desenvolvimento das atividades de pesquisa. Observou-se que os representantes das equipes locais eram, em sua maioria, profissionais de nível superior, sendo $59 \%$ enfermeiros e $82 \%$ contratados como servidores públicos. Apenas dois eram ocupantes de cargo comissionado.

Com a equipe técnica de pesquisa da UEM, foram realizadas seis oficinas (total de 40 horas), sendo duas no período de pré-trabalho de campo e quatro durante o trabalho de campo.

\section{As oficinas com as equipes locais}

Na capacitação das equipes locais apostou-se na promoção do conhecimento e interação entre os sujeitos a partir da resolução de problemas oriundos da prática diária dos técnicos dos municípios envolvidos. Dessa forma, a capacitação ocorreu por meio da participação dos representantes das equipes locais em cinco oficinas presenciais e da realização de atividades de dispersão com acompanhamento das equipes de coordenação e da equipe técnica. Essas ações resultaram na certificação aos participantes de um curso de extensão de 132 horas.

Vale destacar que todas as oficinas contaram com a presença dos coordenadores da pesquisa, dos componentes da equipe técnica e das equipes locais indicadas pelos municípios. Participaram, também, observadores indicados por oito dos 14 municípios que incorporaram outros atores para a constituição de rede de apoio, favorecendo a possibilidade de aprendizado a um maior número de pessoas.

Os módulos presenciais eram realizados em dois dias. No primeiro dia, abordavam-se, por meio de exposição dialogada e dinâmicas de grupo, temas considerados relevantes para a compreensão da importância do planejamento e da avaliação, tais como: SUS, modelos assistenciais, estudos de avaliação de programas de saúde, pesquisa avaliativa, institucionalização da avaliação, construção e aplicação dos instrumentos de pesquisa para estudos avaliativos e indicadores, fontes e sistemas de informação. 
No segundo dia, denominado de período teórico-prático, discutiam-se os instrumentos e as estratégias de pesquisa elaborados em parceria com os técnicos municipais e distribuíam-se as atividades de dispersão ou trabalho de campo. Enfatizavam-se a orientação e supervisão do trabalho de campo, a apresentação de resultados parciais da pesquisa e a avaliação dos trabalhos realizados, especialmente no que se refere às dificuldades encontradas para o cumprimento das atividades de dispersão e às estratégias utilizadas para saná-las.

O desafio inicial consistiu em descobrir as expectativas dos municípios envolvidos e motiválos para a atividade de pesquisa e de construção da metodologia de avaliação.

As duas primeiras oficinas objetivaram realizar um diagnóstico situacional dos vinte municípios em estudo e as demais focalizaram as metodologias utilizadas para avaliação de serviços e programas de saúde.

\section{As atividades de dispersão}

As atividades de dispersão tiveram como objetivo promover o treinamento prático das equipes locais e a coleta de dados para a pesquisa. Os dados foram coletados em fontes primárias e secundárias, obtidos a partir de diferentes técnicas, como observação estruturada e não estruturada, entrevistas com usuários, gestores e trabalhadores de saúde, entrevista em grupo com trabalhadores, análise documental e de diários de campo.

O levantamento da infra-estrutura e dos recursos humanos nos serviços municipais de saúde foi realizado em uma atividade inicial de dispersão denominada Preenchimento de Planilha sobre Capacidade Instalada. Tal atividade objetivou, além de subsidiar o trabalho da equipe de pesquisa, instigar os atores responsáveis pelo manuseio dos dados a partir do reconhecimento das deficiências e qualidades dos sistemas de informação municipais.

Para a realização da atividade de dispersão Entrevista com Gestores, Vereadores e Membros do Conselho Local de Saúde, foi solicitado aos representantes locais uma lista nominal com a relação do todos os vereadores e membros do conselho local de saúde em 2003. Com base nesta, foi feito um sorteio aleatório e, em seguida, encaminhouse aos municípios a lista nominal dos indivíduos que deveriam ser entrevistados, acompanhados de dois nomes de reserva, para o caso de ser necessário fazer alguma substituição.

Para a atividade Entrevista com Usuários, foi feita solicitação de autorização aos hospitais por meio de ofício da equipe coordenadora, entregue pessoalmente nos hospitais por membros das equipes locais. A obtenção dessa autorização ocorreu em $100 \%$ dos municípios.

Considerando que, para atenção ao portador de hipertensão arterial e à mulher no período prénatal, existem critérios de atendimento definidos pelo Ministério da Saúde, elegeu-se a assistência a esses dois seguimentos como condição marcadora 10 . Acredita-se que, por meio dessas condições marcadoras, seria possível avaliar a assistência a esses usuários e indicar a qualidade de outros serviços ambulatoriais, pois a detecção de problemas na assistência ao portador de hipertensão arterial ou no pré-natal pode sugerir que dificuldades semelhantes ocorram em outras áreas.

$\mathrm{O}$ número de puérperas a serem entrevistadas foi definido com base no número de partos realizados no ano de 2004, e o de hipertensos valendo-se do número de internações por doenças cardiovasculares em 2004, informados para cada município na base de dados do DATASUS (Departamento de Informática do SUS).

As entrevistas ocorreram no período de sete dias, em hospitais de referência para a realização dos partos ou em hospitais que, em conjunto, realizavam no mínimo $70 \%$ dos partos encaminhados pelo SUS no município. Entrevistaram-se apenas mulheres residentes no município, cujo pré-natal foi realizado em unidades básicas ou em outras unidades públicas de saúde.

As entrevistas com os hipertensos também ocorreram no período de sete dias, em hospitais que apresentaram maior número de internações pelo SUS de pacientes com diagnóstico de acidente vascular cerebral, crise hipertensiva, insuficiência renal ou outra complicação de hipertensão arterial. Foram entrevistados somente pacientes residentes no município em estudo.

Para a atividade Entrevista com Trabalhadores, fez-se necessário definir os trabalhadores que fariam parte do estudo e, para tanto, realizou-se um sorteio aleatório considerando o número total de trabalhadores e as diferentes categorias profissionais atuantes em cada município. Além disso, foram sorteadas as unidades básicas de saúde nas quais seriam localizados os trabalhadores. Cada município recebeu uma planilha com o demonstrativo do número e da categoria profissional dos trabalhadores que deveriam ser entrevistados.

\section{As visitas técnicas aos municípios}

Foram realizadas duas visitas técnicas a cada um dos municípios em estudo. A primeira visita foi feita pelos membros da equipe técnica. Cada um dos sete representantes dos Preps ficou responsável pelo acompanhamento das atividades desenvolvidas pelas equipes locais de dois ou três 
municípios. Essas visitas foram realizadas entre a terceira e a quarta oficinas de capacitação, com o objetivo de identificar deficiências no apoio e na capacidade de cumprimento das tarefas.

A segunda visita foi feita por integrantes da equipe de coordenação, realizada nos meses de julho e agosto de 2005, com o intuito de verificar o andamento das atividades. Nessa etapa, foram realizadas reuniões com a equipe local e gestores do sistema de saúde municipal, para discussão do processo de pesquisa e reconhecimento da infra-estrutura de planejamento e avaliação nos municípios.

As visitas aos municípios, a supervisão do trabalho e os vários momentos de contato postal, telefônico ou via e-mail possibilitaram, também, o início da vivência em rede e o conhecimento dos fatores limitantes e facilitadores para a realização da pesquisa num escopo participativo. A partir das visitas, foi possível verificar que a maioria dos representantes locais se preocupou em repassar o conteúdo das oficinas para outros técnicos do município e em estabelecer uma organização mínima para a condução das atividades da pesquisa, numa tentativa de institucionalizar a avaliação no seu trabalho.

\section{O banco de dados da produção científica locorregional}

A proposta de construção do banco de dados da produção científica locorregional foi assumida pela equipe por entender que os profissionais da área de saúde carecem de mecanismos que possibilitem a troca de experiências e de informações mais apropriadas ao exercício de suas atividades cotidianas. As informações disponíveis nos bancos de dados e redes de informação não correspondem à qualidade nem à quantidade do que tem sido produzido nesse cotidiano.

Acredita-se que esse banco, no âmbito dos municípios, além de permitir agilidade na atualização e no processo de disseminação do conhecimento, ao minimizar os mecanismos que intermedeiam sua geração e publicação, pode representar uma expansão do modelo de cooperação técnica, promovendo a disseminação descentralizada de fontes de informação multimídia, conectadas em rede, com acesso direto e universal, sem limitações geográficas e de horário. Dessa forma, usuários de diferentes níveis e localizações poderão interagir e navegar no espaço de uma ou várias fontes de informação, independentemente de sua localização física.

Assim, a proposta desenvolvida incluiu os itens mínimos considerados importantes em uma base/banco de dados, mas ela poderá ser enriquecida, reformulada e/ou traduzida em novos produtos e serviços de informação, para atender mais eficientemente às necessidades de informação de usuários específicos.

De acordo com a proposta desenvolvida, as informações serão geradas, atualizadas, armazenadas e operadas na Internet por produtores do conhecimento, no caso os municípios, de modo descentralizado e conforme as metodologias e orientações comuns. Para tanto, cada município receberá uma senha, o que lhe permitirá acesso a um ambiente restrito, no qual serão alteradas ou incluídas novas informações.

A produção científica poderá ser localizada mediante as seguintes referências: (1) por município; (2) por ano da produção; (3) pelo nome do(s) autor(es); (4) pelos descritores; e (5) por palavras do título.

Os dois representantes locais participaram ativamente na primeira etapa de construção desse banco, sendo os responsáveis pelo levantamento inicial da produção científica dos últimos cinco anos em seus municípios, por meio do preenchimento de um instrumento de coleta de dados.

Na segunda etapa, com base na análise dos títulos da produção apresentada, buscouse identificar os estudos que abordassem uma das quatro dimensões utilizadas na avaliação e monitoramento da atenção básica, a saber: integralidade do cuidado, organização da atenção, política institucional e desempenho dos sistemas de saúde. Os municípios foram informados sobre as produções selecionadas e solicitados a apresentar o resumo dessas produções, de forma que elas pudessem ser disponibilizadas no banco de dados. Os representantes locais tiveram o prazo de dois meses para o cumprimento dessa atividade.

\section{Resultados}

Concorda-se com Contandriopoulos 3, para quem a avaliação pode favorecer o aprendizado individual e coletivo; por isso, no processo de investigação, buscou-se envolver um número significativo de pessoas, como pode ser observado na Tabela 1.

Ademais, para estimular o aprendizado, também foi produzido material didático-pedagógico com os conteúdos e textos utilizados nas oficinas pelos pesquisadores convidados. Este foi sintetizado com o título de Atividades de Capacitação e distribuído, no formato de CD-ROM, a todos os municípios e aos membros das equipes técnica e local.

As avaliações formais sobre o conteúdo, a condução da oficina, o desempenho de todo o 
Número de participantes efetivos e colaboradores no processo de pesquisa. Estudo de Linha de Base, Lote 1 Sul, Universidade Estadual de Maringá (UEM), Maringá, Paraná, Brasil, 2006.

\begin{tabular}{lccc}
\hline Participantes & Efetivos & Colaboradores & Total \\
\hline Pesquisadores UEM & 10 & 10 & 20 \\
Equipe estados/regionais & 9 & 2 & 11 \\
Equipe municípios & 37 & 86 & 123 \\
Apoio administrativo & 2 & 3 & 5 \\
Estagiários & 2 & 6 & 8 \\
Total & 60 & 107 & 167 \\
\hline
\end{tabular}

grupo e do trabalho, foram realizadas em todos os módulos presenciais. Elas permitiram identificar que $70 \%$ dos participantes consideraram bom o conteúdo das oficinas, pois estas proporcionaram novos conhecimentos possíveis de serem aplicados em suas ocupações diárias e trouxeram importantes reflexões, ampliando a visão sobre o monitoramento e avaliação. Em adição, configuraram uma oportunidade para discutir condutas e compartilhar sentimentos relacionados ao tema.

A condução dos trabalhos foi considerada objetiva e unificadora das decisões do grupo, sendo avaliada como excelente ( $40 \%$ ) ou boa (55\%), enquanto o desempenho de todo o grupo e do trabalho desenvolvido foi julgado bom por $65 \%$ dos participantes e excelente por $30 \%$ deles.

A análise dos registros dos diários de campo referente às oficinas com as equipes locais demonstrou que as estratégias utilizadas contribuíram para a sensibilização dos atores acerca da importância da avaliação e do planejamento em saúde, o que foi identificado a partir da diminuição da ansiedade de alguns participantes quanto à compreensão do processo de pesquisa e à falta de tempo para aplicar os instrumentos desta.

A participação dos representantes locais nas oficinas foi considerada positiva, pois teve uma média de 37,5 participantes (para um total esperado de 40). A periodicidade dos encontros (bimensais) foi considerada adequada pela maioria dos participantes, embora alguns técnicos tenham encontrado dificuldades em participar de alguns módulos.

Quanto à atuação dos municípios em relação ao cumprimento das atividades de dispersão, observamos que os municípios em geral, com maior ou menor grau, envolveram-se com as atividades propostas e entenderam a importância destas no processo de capacitação para a avaliação em saúde.
O Preenchimento da Planilha sobre Capacidade Instalada demonstrou a fragilidade dos sistemas de tratamento dos dados e a dificuldade dos técnicos da equipe local para registrar e compilar as informações, pois o instrumento retornou várias vezes para discussão e correções. Ao final da compilação e análise dos dados, observou-se que os dados produzidos pelos municípios não coincidiam com aqueles da base de dados oficiais, como, por exemplo, o Cadastro Nacional de Estabelecimento de Saúde (CNES). Isso revela que a multiplicidade de fontes de registro não permite atualização adequada, obstaculizando a confiabilidade de informações, muitas vezes fundamentais para a avaliação da atenção.

Para a realização de Entrevista com Gestores, Vereadores e Membros do Conselho Local de Saú$d e$, fez-se necessário ampliar o prazo inicialmente estabelecido para o cumprimento dessa atividade, já que muitos municípios tiveram dificuldade em conseguir localizar alguns indivíduos sorteados, bem como em conseguir que alguns concordassem com a entrevista e dispusessem de horário para sua concessão.

O fato de se utilizar o ano de 2003 como referência para as entrevistas com os vereadores ocasionou alguns problemas, visto que alguns dos sorteados já tinham se mudado do município e outros se recusaram a participar por vinculação político-partidária e por não fazerem mais parte da gestão municipal. Considerando-se a possibilidade de substituição, esta tarefa foi cumprida pelos vinte municípios, porém foi a atividade que apresentou maior perda (Tabela 2).

A realização de Entrevista com Usuários foi muito bem aceita pela maioria dos membros das equipes locais, embora, à primeira vista, alguns municípios tenham considerado o número de indivíduos a serem entrevistados muito grande. Contudo, mesmo nesses municípios, a atividade só não foi cumprida integralmente em virtude 
Número de entrevistas previstas e realizadas por município, primeira fase de pesquisa. Estudo de Linha de Base, Lote 1 Sul, Universidade Estadual de Maringá, Maringá, Paraná, Brasil, janeiro de 2006.

\begin{tabular}{|c|c|c|c|c|c|c|c|c|c|c|c|c|}
\hline \multirow[t]{2}{*}{ Município } & \multicolumn{2}{|c|}{ Conselheiros } & \multicolumn{2}{|c|}{ Vereadores } & \multicolumn{2}{|c|}{ Trabalhadores } & \multicolumn{2}{|c|}{ Puérperas } & \multicolumn{2}{|c|}{ Hipertensos } & \multicolumn{2}{|c|}{ Total * } \\
\hline & Prevista & Realizada & Prevista & Realizada & Prevista & Realizada & Prevista & Realizada & Prevista & Realizada & $\begin{array}{c}\text { Entre- } \\
\text { vistados }\end{array}$ & Perdas \\
\hline Apucarana & 3 & 3 & 4 & 3 & 10 & 10 & 7 & 7 & 11 & 9 & 35 & 3 \\
\hline Araucária & 3 & 3 & 3 & 3 & 13 & 13 & 8 & 8 & 7 & 7 & 32 & - \\
\hline Blumenau & 3 & 3 & 4 & 4 & 25 & 25 & 16 & 16 & 24 & 24 & 72 & - \\
\hline Cascavel & 3 & 2 & 4 & 4 & 26 & 26 & 17 & 17 & 21 & 21 & 71 & 1 \\
\hline Colombo & 3 & 2 & 3 & 2 & 9 & 9 & 16 & 16 & 16 & 16 & 47 & 2 \\
\hline Curitiba & 3 & 3 & 6 & 2 & 89 & 89 & 107 & 106 & 98 & 91 & 312 & 12 \\
\hline Foz do Iguaçu & 3 & 3 & 4 & 4 & 17 & 13 & 22 & 23 & 14 & 14 & 60 & 4 \\
\hline Guarapuava & 3 & 3 & 4 & 4 & 10 & 12 * & 13 & 13 & 13 & 13 & 43 & - \\
\hline Itajaí & 3 & 3 & 5 & 5 & 16 & 16 & 10 & 10 & 14 & 14 & 48 & - \\
\hline Jaraguá do Sul & 3 & 2 & 4 & 2 & 5 & 5 & 7 & 6 & 6 & 4 & 47 & 6 \\
\hline Joinville & 3 & 3 & 4 & 2 & 32 & 28 & 29 & 29 & 22 & 11 & 68 & 17 \\
\hline Londrina & 3 & 3 & 4 & 4 & 30 & 29 & 29 & 29 & 34 & 35 & 100 & 1 \\
\hline Maringá & 3 & 3 & 4 & 4 & 23 & 23 & 17 & 17 & 23 & 23 & 70 & - \\
\hline Palhoça & 3 & 3 & 4 & 3 & 5 & 5 & 7 & 7 & 8 & 6 & 27 & 3 \\
\hline Paranaguá & 3 & 3 & 4 & 3 & 8 & 8 & 11 & 11 & 8 & 6 & 34 & 3 \\
\hline Pinhais & 3 & 3 & 3 & 1 & 6 & 6 & 9 & 9 & 8 & 1 & 29 & 9 \\
\hline Ponta Grossa & 3 & 3 & 4 & 3 & 16 & 16 & 22 & 22 & 22 & 19 & 67 & 4 \\
\hline São José & 3 & 2 & 4 & 3 & 11 & 11 & 11 & 11 & 11 & 11 & 240 & 2 \\
\hline São José dos Pinhais & 3 & 3 & 4 & 4 & 13 & 13 & 17 & 17 & 15 & 11 & 452 & 4 \\
\hline Toledo & 3 & 3 & 4 & 4 & 5 & 4 & 6 & 7 & 9 & 10 & 27 & - \\
\hline Total realizado & 60 & 56 & 80 & 64 & 369 & 361 & 381 & 381 & 384 & 346 & 1.208 & - \\
\hline Perdas & 4 & $6,6 \%$ & 16 & $20,0 \%$ & 8 & $2,17 \%$ & - & - & 38 & $9,8 \%$ & - & 66 \\
\hline
\end{tabular}

* Foram realizadas, ainda, entrevistas com todos os secretários e diretores de saúde ou coordenadores do Programa Saúde da Família em exercício da função no ano de 2003.

da não-internação de indivíduos, em especial os hipertensos, que atendessem aos critérios e ao prazo previamente estabelecido. Esta foi uma das atividades em que mais se observou a importância da existência de uma equipe de apoio para o seu cumprimento.

A atividade Entrevista com Trabalhadores foi cumprida integralmente pelos 20 municípios, e no geral ocorreu perda de cerca de $2 \%$ da amostra.

$\mathrm{Na}$ Tabela 2, é possível verificar o desempenho de cada município no cumprimento das atividades de dispersão, observando-se que seis municípios não apresentaram nenhuma perda e que, proporcionalmente, os municípios que apresentaram maiores perdas foram: Pinhais (23,7\%), Joinvile (20\%) e Ponta Grossa $(17,7 \%)$. Em relação às atividades, observa-se que a maior proporção de perdas ocorreu na entrevista com vereadores (20\%), seguida dos hipertensos $(9,8 \%)$, sendo esta última justificada pelos municípios pela não-internação do número indicado no prazo estabelecido.
Em relação à construção do banco de dados da produção científica locorregional, observa-se, na Tabela 3, que no prazo previamente estabelecido - início de setembro de 2005 - os representantes locais conseguiram levantar em seus municípios um total de 327 títulos de produção científica produzida localmente. Nesta etapa, apenas o Município de Jaraguá do Sul não apresentou nenhuma produção científica.

Ao se investigar a natureza e a temática abordada, observou-se que cerca de um terço (122) das produções apresentadas correspondia a produção científica e estava relacionada com uma das quatro dimensões da avaliação e monitoramento da Atenção Básica, visto que muito das produções apresentadas constituía-se de relatórios técnicos de gestão. Na segunda etapa, apenas dois municípios apresentaram o resumo de todas as produções indicadas para entrar no banco de dados e sete municípios não apresentaram nenhum resumo. Com a prorrogação de quase três meses no prazo para apresentação dos 
Distribuição da produção científica locorregional. Estudo de Linha de Base, Lote 1 Sul, Universidade Estadual de Maringá, Maringá, Paraná, Brasil, 2006.

\begin{tabular}{|c|c|c|c|c|c|}
\hline \multirow[t]{2}{*}{ Município } & \multirow{2}{*}{$\begin{array}{c}\text { Produções } \\
\text { apresentadas } \\
\text { na etapa } 1\end{array}$} & \multirow{2}{*}{$\begin{array}{c}\text { Produções } \\
\text { selecionadas }\end{array}$} & \multicolumn{2}{|c|}{ Resumos apresentados } & \multirow{2}{*}{$\begin{array}{l}\text { Produção total } \\
\text { inclusa no } \\
\text { banco de dados }\end{array}$} \\
\hline & & & 1으 & 2oㅇ & \\
\hline Araucária/PR & 24 & 10 & - & - & - \\
\hline Apucarana/PR & 6 & 5 & 3 & 1 & 4 \\
\hline Blumenau/SC & 10 & 4 & 3 & - & 3 \\
\hline Cascavel/PR & 17 & 9 & - & 11 & 11 \\
\hline Colombo/PR & 23 & 17 & 16 & - & 16 \\
\hline Curitiba/PR & 66 & 16 & 13 & 10 & 23 \\
\hline Foz do Iguaçu/PR & 9 & 3 & 9 & - & 9 \\
\hline Guarapuava/PR & 10 & 2 & 6 & 2 & 8 \\
\hline Itajaí/SC & 21 & 8 & 3 & 1 & 4 \\
\hline Jaraguá do Sul/SC & - & - & - & - & - \\
\hline Joinville/SC & 14 & 8 & 6 & - & 6 \\
\hline Londrina/PR & 14 & 5 & - & 28 & 28 \\
\hline Maringá/PR & 6 & - & 31 & 46 & 77 \\
\hline Palhoça/SC & 5 & 3 & - & - & - \\
\hline Paranaguá/PR & 3 & 2 & - & - & - \\
\hline Pinhais/PR & 3 & 1 & 1 & - & 1 \\
\hline Ponta Grossa/PR & 21 & 11 & - & 30 & 30 \\
\hline São José/SC & 9 & 4 & 4 & - & 4 \\
\hline São José dos Pinhais/PR & 12 & 6 & 1 & - & 1 \\
\hline Toledo/PR & 54 & 8 & 17 & - & 17 \\
\hline Total & 327 & 122 & 113 & 129 & 242 \\
\hline
\end{tabular}

PR: Paraná; SC: Santa Catarina.

resumos, alguns municípios conseguiram localizar novas produções que se enquadravam nos critérios estabelecidos, de modo que o banco de dados ficou constituído por 242 produções científicas locorregionais de 16 dos 20 municípios em estudo.

As dificuldades encontradas pelos representantes locais para levantar a produção científica em seus municípios constituem, por si só, um indicativo da importância da construção desse banco. A partir do momento em que os municípios tiverem acesso ao banco de dados da produção científica, acredita-se que será despertado o interesse em estimular e incitar a produção do conhecimento, bem como de divulgar o que tem sido produzido.

Espera-se, ainda, que a existência desse banco também venha a motivar os gestores a realizar um controle do que é produzido sobre o sistema de saúde de seus municípios. Se o serviço funcionou como campo para a coleta de dados, o resultado final precisa ser devolvido ao município e, ao mesmo tempo, ficar disponível para consulta e conhecimento.
Compreende-se também que haverá maior preocupação em tornar a informação disponível. Alguns municípios - como Curitiba, Londrina, Joinville e outros - realizam encontros científicos com diferentes denominações (por exemplo, Mostra de Saúde e Encontros de Saúde Coletiva), durante os quais são apresentados estudos e relatos de experiências, divulgados de forma impressa ou digital em anais, cuja distribuição é restrita aos participantes. Doravante, portanto, os municípios poderão divulgar essa produção no Banco de Dados da Produção Científica Locorregional, que estará alocado no Ministério da Saúde.

\section{Considerações sobre o processo de pesquisa}

A metodologia utilizada no desenvolvimento da pesquisa foi um tanto ousada e, sem dúvida alguma, trabalhosa e demorada, pois se apostou na possibilidade de capacitar os profissionais de forma concomitante ao próprio desenvolvimento da pesquisa. A adoção dos princípios da pes- 
quisa-ação, rumo à construção coletiva, exigiu a inclusão dos representantes municipais desde o primeiro momento da investigação. Todos reafirmaram a importância do apoio das instituições de ensino para a implementação de projetos avaliativos da oferta de serviços, em face da dificuldade de permanência dos trabalhadores nos cargos e do fato de os modelos assistenciais serem adotados e modificados a cada troca de gestão: em apenas dois dos vinte municípios, por exemplo, os secretários permaneceram no cargo após 2004.

A discussão coletiva da metodologia e dos instrumentos utilizados na pesquisa e a participação ativa no processo possibilitaram maior integração entre os representantes dos serviços e os da academia. No entanto, fizeram aumentar o tempo destinado à coleta de informações realizada pelos primeiros, que nem sempre dispunham de tempo para a atividade proposta, pois continuavam a exercer suas funções em seus municípios.

A falta de tempo para a realização das entrevistas ou para a coleta de informações também prejudicou, em alguns momentos, a confiabilidade dos dados e dificultou a interpretação de alguns resultados. Ressaltou-se, assim, o fato de os municípios contarem com condições desfavoráveis por disporem de número insuficiente de pessoas para o planejamento e a avaliação dos serviços, em alguns deles sob a responsabilidade de um único sujeito.

É importante considerar que a metodologia dependia da confiabilidade das informações, e as produzidas durante o processo algumas vezes mostraram-se inadequadas porque apresentavam inconsistências entre os sistemas locais de tratamento e as bases oficiais de dados, com problemas nos resultados e discrepâncias entre as coberturas potencial e real. Isso dificultou investigar se as ações previstas foram implementadas adequadamente ou não.

O trabalho de campo caracterizou-se como um processo rico de trocas de experiência entre os serviços e a academia, numa via de mão dupla. O processo de capacitação e as estratégias adotadas para tal foram avaliados positivamente pela maioria dos participantes. A avaliação dos profissionais com relação à sua participação no processo de construção e desenvolvimento da metodologia da pesquisa foi positiva. Eles ressaltaram a importância das ações realizadas e da troca de experiências entre os municípios na compreensão de aspectos relacionados com avaliação, em relação, inclusive, à proposta da pesquisa e à sua formação pessoal enquanto profissionais e trabalhadores de um município em avaliação. Relataram que a capacitação teórico- prática possibilitou a implantação da avaliação no município.

Os diários de campo revelaram também que as estratégias utilizadas tornaram possível a capacitação dos profissionais como uma estrutura potencializadora do processo de institucionalização da avaliação. Isso porque demonstraram que as equipes locais tiveram participação ativa durante todo o processo e que as oficinas oportunizaram o esclarecimento de dúvidas, além de constituírem espaço apropriado para a discussão coletiva de dificuldades cotidianas relacionadas com a avaliação e o monitoramento dos serviços de saúde. As discussões coletivas tinham forte adesão dos participantes a essa forma de metodologia, revelando-se prazerosas.

No que se refere à resposta dos representantes locais aos objetivos do estudo, é possível afirmar que, embora nem todos tenham permanecido durante todo o processo de pesquisa, a grande maioria demonstrou comprometimento e responsabilidade para integrar a equipe de trabalho, cumprindo com brevidade as atividades pactuadas. Além disso, 14 municípios incorporaram outros atores no nível local e, após reprodução dos conteúdos abordados nas oficinas, constituíram redes de apoio para execução das atividades de campo.

Considerando-se a disponibilidade de técnicos para a coleta de dados, a cessão de infra-estrutura e a constituição de redes de apoio, em 12 municípios houve forte adesão à proposta; em seis a adesão foi intermediária e em dois deles a adesão foi considerada fraca.

O levantamento e discussão sobre a produção científica locorregional nos municípios e sobre as dificuldades para localizá-la constituíram motivação para iniciar tentativas de organização dessas questões, além de despertar os representantes para a importância de divulgar o que o serviço tem produzido. Nesse sentido, como última etapa da capacitação dos trabalhadores, a equipe coordenadora se dispôs a assessorar os membros das equipes locais na elaboração de artigos científicos abordando aspectos do monitoramento e avaliação em saúde de seus municípios.

A investigação nos diversos municípios demonstrou que, para implementar uma efetiva avaliação do desempenho dos serviços, faz-se necessário um processo amplo de pactuação entre os diferentes atores. Também ressaltou a importância de se estabelecerem sistemas de monitoramento dos indicadores municipais, com métodos e técnicas de exploração e análise das informações, necessários para dar conta dos diferentes processos de vida em sociedade, com adequada forma de assistir. 
Para além dos desafios, a realização da pesquisa foi instigante e reafirmou para o grupo a importância da integração entre a universidade e o serviço. Envolveu alunos de graduação e pós-

\section{Resumo}

Este artigo relata a trajetória metodológica utilizada pela equipe de pesquisa da Universidade Estadual de Maringá no Estudo de Linha de Base, em vinte municípios com mais de 100 mil habitantes dos Estados do Paraná e Santa Catarina, Brasil na implantação do Projeto de Expansão e Consolidação do Saúde da Família (PROESF). Foram realizadas oficinas para a discussão de estudos de avaliação de programas, construção e aplicação de instrumentos de pesquisa, visitas técnicas aos municípios para supervisão das atividades de dispersão e construção de um banco de dados com a produção científica locorregional. Foi possível verificar responsabilidade e compromisso dos representantes municipais e estaduais, visto que a maior parte respondeu prontamente às atividades acordadas, além de interesse no aprendizado e na institucionalização da avaliação. Quatorze municípios incorporaram outros atores para a constituição de rede de apoio para a avaliação da atenção básica, e as estratégias contribuíram para que a avaliação fosse incorporada ao planejamento, indicando que a capacitação pode ser estruturante e potencializadora do processo de institucionalização da avaliação.

Atenção Primária à Saúde; Avaliação em Saúde; Programa Saúde da Família; Capacitação

\section{Colaboradores}

M. J. Scochi e S. S. Marcon foram responsáveis pela concepção e redação final do texto e do processo de capacitação. M. A. P. Waidman, M. L. F. Oliveira e W. O. Carvalho, M. B. Gonçalves, P. Nishiyama e R. L. D. T. Silva, participaram na análise e interpretação dos resultados, na redação do texto e no processo de capacitação.

\section{Agradecimentos}

Ao Ministério da Saúde pelo apoio no desenvolvimento do estudo. graduação, produzindo novos olhares sobre os processos de trabalho, de ensino e de aprendizagem.

\section{Referências}

1. Secretaria de Atenção à Saúde. Avaliação na atenção básica em saúde: caminhos da institucionalização. Brasília: Coordenação de Avaliação e Acompanhamento da Atenção Básica, Ministério da Saúde; 2005.

2. Bodstein R. Institucionalização da avaliação como estratégia de fortalecimento da atenção básica. Boletim ABRASCO 2005; (94):14-5.

3. Contandriopoulos AP. Avaliando a institucionalização da avaliação. Ciênc Saúde Coletiva 2006; 11: 705-11.

4. Felisberto E. Monitoramento e avaliação na atenção básica: novos horizontes. Rev Bras Saúde Matern Infant 2004; 4:317-21.

5. Martelo RM, Silva ABO. Redes e capital social: o enfoque da informação para o desenvolvimento local. Ciênc Inf 2004; 33:41-19.

6. Macedo TMB. Redes informais nas organizações: a co-gestão do conhecimento. Ciênc Inf 1999; 28: 94-100.

7. Guba EG, Lincoln YS. Fourth generation evaluation. London: Sage Publications; 1989.

8. Gonçalves VLM, Leite MMJ, Ciampone MHT A pesquisa-ação como método para reconstrução de um processo de avaliação de desempenho. Cogitare Enferm 2004; 9:50-9.

9. Almeida VP. Avaliação de programas sociais: de mensuração de resultados para uma abordagem construtivista. Pesquisas e Práticas Psicossociais 2006; 1(2). http://www.ufsj.edu.br/Pagina/ppplapip/numero_2.php (acessado em 15/Jun/2007).

10. Kessner DM, Kalk CE, Singer J. Assessing health quality: the case for tracers. N Engl J Med 1973; 28:189-94.

Recebido em 10/Nov/2006

Versão reapresentada em 11/Jul/2007

Aprovado em 09/Ago/2007 